\title{
Genetic parameters and genetic gain for the reproduction traits in Latvian Landrace and Yorkshire sows populations
}

\author{
Liga Paura ${ }^{1,}$, , Daina Jonkus², Ugis Permanickis ${ }^{3}$ \\ ${ }^{1}$ Department of Control Systems, Latvia University of Agriculture, Jelgava, Latvia \\ ${ }^{2}$ Institute of Agrobiotechnology, Latvia University of Agriculture, Jelgava, Latvia \\ 3"Gensoft" Ltd, Saldus District, Latvia
}

Email address:

liga.paura@1lu.lv (L. Paura), daina.jonkus@1lu.lv (D. Jonkus)

\section{To cite this article:}

Liga Paura, Daina Jonkus, Ugis Permanickis. Genetic Parameters and Genetic Gain for the Reproduction Traits in Latvian Landrace and Yorkshire Sows Populations. Animal and Veterinary Sciences. Vol. 2, No. 6, 2014, pp. 184-188. doi: 10.11648/j.avs.20140206.15

\begin{abstract}
The aim of this study was to estimate genetic parameters for the reproduction traits of Landrace and Yorkshire sows and to analyze the genetic gain in these Latvian swine populations. Records of 14577 first-parity and 27359 later-parities Landrace sows and 6039 first-parity and 12360 later-parities Yorkshire sows born between 2000 and 2012 were included in the analysis. The number of piglets born alive and 21-day litter weight at first and later parities, and weaning-conception interval between the first and second parity were included in the study. The genetic parameters were estimated using a single-trait animal model for the first parity and a single-trait repeatability animal model for later parities using REML procedure. Compared to heritability estimates for number born alive, heritabilities for litter weight were higher in both populations: in the first parity $0.10 \pm 0.015$ vs. $0.31 \pm 0.021$ for Landrace, and $0.05 \pm 0.016$ vs. $0.23 \pm 0.028$ for Yorkshire; in later parities $0.10 \pm 0.010$ vs. $0.23 \pm 0.013$ for Landrace, and $0.10 \pm 0.017$ vs. $0.20 \pm 0.022$ for Yorkshire. The heritability of reproduction traits was low; however, during the last ten years, reproduction traits in nucleus herds were improving. The results show that genetic progress in the last five years has been relatively low.
\end{abstract}

Keywords: Heritability, Litter Size, Pigs, Repeatability

\section{Introduction}

Two maternal breeds - Landrace and Yorkshire - are used in the swine breeding programme in Latvia. In pig breeding (nucleus) farms, the population of Landrace sows is $25.2 \%$ larger than that of Yorkshire sows due to their maternal effects [13]. The breeding goals for the maternal breed in the swine selection program in Latvia for 2011-2016 are: number born alive - up to 11.5 piglets per litter; the number of piglets weaned per sow per year - up to 25 piglets; the weaning-conception interval - 11 days; the number of teats at least 14 [13].

The Norsvin Landrace selection programme for dam line includes a total of 25 different traits with weighting, comprising not only the number of live-born piglets but also such traits as pig mortality (included in 2010) and sow body-condition score at weaning (included in 2012).

Grandinson et al. [4] investigated the Swedish Yorkshire swine population and found significant genetic correlations between the changes in sow weight and backfat during lactation and in piglet survival and growth. Consequently, the researchers advised to include these traits in the selection programme for improvement of piglet survival and growth.

According to investigations carried out by $\mathrm{Su}$ et al. [11] in Denmark, changing the selection criteria of maternal breed from the total number born to litter size at day five (LP5) improves the litter size at weaning and the piglet survival rate. In the result, LP5 after farrowing was included in the breeding goal for three-breed dam lines.

The Landrace and Yorkshire sow selection in Latvia is based on the total merit index. Since 1999, evaluations for the production and reproduction traits are performed independently by using the PIGBLUP package. The gilt and sow reproduction traits are defined as separate traits, and evaluation of sow reproduction traits number of piglets born alive (NBA1), 21-day litter weight (LW1) and weaning-conception interval (WCI) is performed in the first parity, and that number of piglets born alive (NBA2+) and 21-day litter weight (LW2+) is performed in later parities. The single-trait BLUP animal model is used to evaluate the first-parity reproduction traits, and the repeatability-traits 
BLUP animal model is used to evaluate later-parity reproduction traits.

The genetic parameters currently used in the Latvian Landrace (LL) and Latvian Yorkshire (LY) evaluation conform to the PIGBLUP program and are not specific for breeds.

The objective of this study was to estimate the genetic parameters and genetic trend for Landrace and Yorkshire sow reproduction traits in the first and later parities by animal model. Such results are prerequisite parameters in the breeding value estimation.

\section{Material and Methods}

\subsection{Data}

The data used in this study were obtained from the Pig Breeding Centre (CCC), which operates the national recording scheme.

The data included 60335 reproductive performance records on the first- and later-parity LL and LY sows born in the nucleus herds from January 2000 to December 2012 (Table 1).
The following traits were extracted: sow's identity, identification number of each sow's parent, sow's birth date, mating and farrowing date, herd, year, lactation length, NBA, LW, number weaned per litter (NW), and WCI.

Age at first farrowing (AFF) was defined as the interval (in days) from the birth of the sow to her farrowing. The trait NBA represents the number of piglets alive until $24 \mathrm{~h}$ after birth. NW includes the number of piglets until weaning and the number of cross-fostered piglets. The trait LW was adjusted to 21-day litter weight from the observed weight and was standardised to 10 piglets. WCI was defined as the interval from weaning to successful insemination.

Individual records were set to the missing value when not observed within the intervals that are used in the actual sow evaluation: 250 to 480 days for AFF; 1 to 60 days for WCI; 1 to 25 piglets for NBA1 and NBA2+; and 10 to $140 \mathrm{~kg}$ for LW1 and LW2+, respectively. Afterwards, for LL sows, 14577 and 27359 records were available in the first and later parities, respectively; for LY sows, 6039 and 12360 records were available in the first and later parities, respectively (Table1).

Table 1. The number of sow records, dams, sires, and records per dam and sire by breed

\begin{tabular}{lllllll}
\hline Breed & Parity & Records of sows & Dams & Sires & Records per dam & Records per sire \\
\hline LL & 1st & 14577 & 5823 & 516 & 2.5 \\
& 2nd + & 27359 & 4580 & 471 & 5.9 \\
LY & 1st & 6039 & 2770 & 275 & 2.3 \\
& 2nd + & 12360 & 2253 & 259 & 21.96 \\
\hline
\end{tabular}

\subsection{Statistical Analysis}

To evaluate heritabilities, the single-trait animal model was used for first-parity sow traits and the single-trait repeatability animal model was used for later-parity sow traits: first parity:

$$
\mathrm{y}_{\mathrm{i}}=\mu+\mathrm{HY}_{\mathrm{i}}+\mathrm{A}_{\mathrm{m}}+\mathrm{e}_{\mathrm{ime}},
$$

later parities:

$$
\mathrm{y}_{\mathrm{i}}=\mu+\mathrm{HY}_{\mathrm{i}}+\mathrm{P}_{\mathrm{j}}+\mathrm{A}_{\mathrm{m}}+\mathrm{PE}_{\mathrm{n}}+\mathrm{e}_{\mathrm{ijmn}},
$$

WCI

$$
\mathrm{y}_{\mathrm{i}}=\mu+\mathrm{HY}_{\mathrm{i}}+\mathrm{AFF}_{\mathrm{j}}+\mathrm{LG}_{\mathrm{k}}+\mathrm{NW}_{1}+\mathrm{A}_{\mathrm{m}}+\mathrm{e}_{\mathrm{ijklme}},
$$

where $y_{i}$ represents the values of reproductive traits.

The models include the fixed effects of

- herd-year (HY),

- parity $(\mathrm{P})$,

- age at first farrowing (AFF),

- lactation length (LG), and

- number of weaned piglets (NW).

AFF was divided into eight classes: $\leq 274$, 295-304, $305-314,215-334,335-354,355-374,375-399$, and $\geq 400$ days.

LG was grouped into five intervals: till 20 days; from 30 days; from 21 to 29 days - three intervals, each three days long.

NW was formed into six classes: $\leq 6,7,8,9,10$, and $\geq 11$ piglets.
The permanent environmental effect of the sow (PE) and additive genetic effects of the animal (A) were fitted in the model.

Genetic parameters (heritability and repeatability) of reproduction traits were estimated by REML method using WOMBAT software [9] applying animal model. Heritability was defined as the ratio of the additive genetic variance to phenotypic variance $\left(\mathrm{h}^{2}=\mathrm{Va} / \mathrm{Vp}\right)$; repeatability was defined as the ratio of the sum of the additive genetic variance and permanent environmental variance to the phenotypic variance $\left(\mathrm{r}_{\mathrm{w}}=(\mathrm{Va}+\mathrm{Vpe}) / \mathrm{Vp}\right)$. The data in tables are represented as mean \pm standard error.

\section{Results}

\subsection{Phenotypic Information}

The LL sows are characterized by a higher NBA and LW in the first and later parities than LY sows. The average NBA for LL sows was 9.9 at first parity and 11.2 piglets per litter at later parities; for LY breed sows -9.3 and 10.9 piglets, respectively (Table2).

The percentage of LL sows with more than five piglets born alive was $94 \%$ at first parity and $97.6 \%$ at later parities.

In LY population, first-parity sows had a lower NBA (only $89.9 \%$ of sows had more than five piglets born alive) than LL sows, but for later-parity sows this trait was the same as in LL swine population $(97.8 \%$ of sows had more than five piglets born alive). The highest number of piglets born alive at first parity was 20 for LL sows and 19 for LY sows; at later parities, 
there were at maximum 22 piglets per litter.

The average LW in LL population was $59.2 \mathrm{~kg}$ (first parity) and $67.3 \mathrm{~kg}$ (later parities), which corresponds to the average piglet weight in the first and later parities $-6.4 \mathrm{~kg}$ and $6.5 \mathrm{~kg}$, respectively. The data showed that LY breed population had a lower LW than LL breed.
The mean WCI, which represents the period from weaning to successful insemination between first and second parity, was on average 13.0 days for LL sows and 11.5 days for LY sows. The records that surpassed 60 days, namely, $9.7 \%$ for LL sows and $10.1 \%$ for LY sows, were excluded from the analysis.

Table 2. Summary statistics for litter traits for the first and later parities by breed

\begin{tabular}{|c|c|c|c|c|c|c|}
\hline Breed & Traits/Factors & Abbreviation & Mean & SD & Min & Max \\
\hline \multirow[t]{10}{*}{ Landrace } & 1st parity $(n=14577)$ & & & & & \\
\hline & Age at first farrowing (days) & AFF & 359.4 & 31.74 & 277 & 480 \\
\hline & Number born alive (piglets) & NBA1 & 9.9 & 2.96 & 1 & 20 \\
\hline & Number weaned (piglets) & NW1 & 9.3 & 2.94 & 2 & 16 \\
\hline & Lactation length (days) & LG1 & 28.4 & 3.91 & 9 & 61 \\
\hline & Litter weight at 21 day $(\mathrm{kg})$ & LW1 & 60.2 & 8.20 & 20 & 103.8 \\
\hline & $\begin{array}{l}\text { Weaning-conception interval } \\
2 n d+\text { parities }(n=27359)\end{array}$ & WCI & 13.0 & 15.62 & 1 & 60 \\
\hline & Number born alive (piglets) & $\mathrm{NBA} 2+$ & 11.2 & 2.92 & 1 & 22 \\
\hline & Number weaned (piglets) & NW2+ & 10.4 & 1.62 & 1 & 17 \\
\hline & Litter weight at 21 day $(\mathrm{kg})$ & LW2+ & 65.2 & 8.64 & 21 & 108 \\
\hline \multirow[t]{8}{*}{ Yorkshire } & 1st parity $(n=6039)$ & & & & & \\
\hline & Age at first farrowing (days) & AFF & 375.9 & 44.42 & 284 & 480 \\
\hline & Number born alive (piglets) & NBA1 & 9.3 & 2.92 & 1 & 19 \\
\hline & Number weaned (piglets) & NW1 & 10.1 & 1.66 & 3 & 15 \\
\hline & $\begin{array}{l}\text { Weaning-conception interval } \\
2 \mathrm{nd}+\text { parities }(\mathrm{n}=12360)\end{array}$ & WCI & 11.5 & 14.76 & 1 & 60 \\
\hline & Number born alive (piglets) & NBA2+ & 10.9 & 2.81 & 0 & 22 \\
\hline & Number weaned (piglets) & NW2+ & 10.2 & 1.61 & 0 & 15 \\
\hline & Litter weight at 21 day $(\mathrm{kg})$ & LW2+ & 62.9 & 9.92 & 20 & 110 \\
\hline
\end{tabular}

Table 3. Estimated variance components $(V)$, heritability $\left(h^{2}\right)$ and repeatability $\left(r_{w}\right)$ of performance traits in the first and later parities by breed (2000-2012)

\begin{tabular}{llllll}
\hline Traits & Va & Vpe & Ve & $\mathbf{h}^{2} \pm \mathbf{S}_{\mathbf{h}}$ & $\mathbf{r}_{\mathbf{w}} \pm \mathbf{S}_{\mathbf{w}}$ \\
\hline LL & & & & & \\
AFF & 187.7 & - & 725.3 & $0.21 \pm 0.019$ & - \\
NBA1 (piglets) & 0.77 & - & 7.03 & $0.10 \pm 0.015$ & - \\
LW1 (kg) & 16.98 & - & 37.03 & $0.31 \pm 0.021$ & - \\
WCI & 29.62 & - & 208.67 & $0.12 \pm 0.016$ & - \\
NBA2+ (piglets) & 0.84 & 0.61 & 6.85 & $0.10 \pm 0.010$ & $0.17 \pm 0.007$ \\
LW2+ (kg) & 14.18 & 1.09 & 46.48 & $0.23 \pm 0.013$ & $0.25 \pm 0.008$ \\
LY & & & & & \\
AFF & 175.3 & - & 706.5 & $0.20 \pm 0.015$ & - \\
NBA1 (piglets) & 0.45 & - & 8.07 & $0.05 \pm 0.016$ & - \\
LW1 (kg) & 17.49 & - & 58.89 & $0.23 \pm 0.028$ & - \\
WCI & 7.43 & - & 189.53 & $0.04 \pm 0.018$ & - \\
NBA2+ (piglets) & 0.79 & 0.68 & 6.45 & $0.10 \pm 0.017$ & $0.19 \pm 0.012$ \\
LW2+ (kg) & 18.97 & 14.35 & 63.11 & $0.20 \pm 0.022$ & $0.35 \pm 0.012$ \\
\hline
\end{tabular}

+ See Table 2 for abbreviations of the traits.

\subsection{Genetic Parameters}

Estimates of genetic parameters (genetic variances and heritability) using animal models for the first and later parities are presented in Table 3 . In both swine populations, the estimated heritability for NBA per litter of piglets at first parity was low and similar to that of later parities $0.05-0.1$. The lowest heritability estimate was for WCI, namely, $\mathrm{h}^{2}=0.04$. The highest direct heritability was estimated for LW at first parity $\left(h^{2}=0.31\right.$ for LL breed; $h^{2}=0.23$ for LY breed $)$; the coefficients were moderate.
$\mathrm{NBA} 2+$ and LW2 + were analysed as a repeated trait within the LL and LY populations. The estimates of repeatability for these traits were moderate, though with slightly higher values for LW2+: $r_{w}=0.25$ for LL breed, and $r_{w}=0.35$ for LY breed.

\subsection{Genetic Gain}

Figures 1 to 3 present the genetic trends in breeding values of reproduction traits in 2000-2012. In the analyzed period, a positive response was observed for NBA, LW and WCI in the first and later parities of both breed sows.

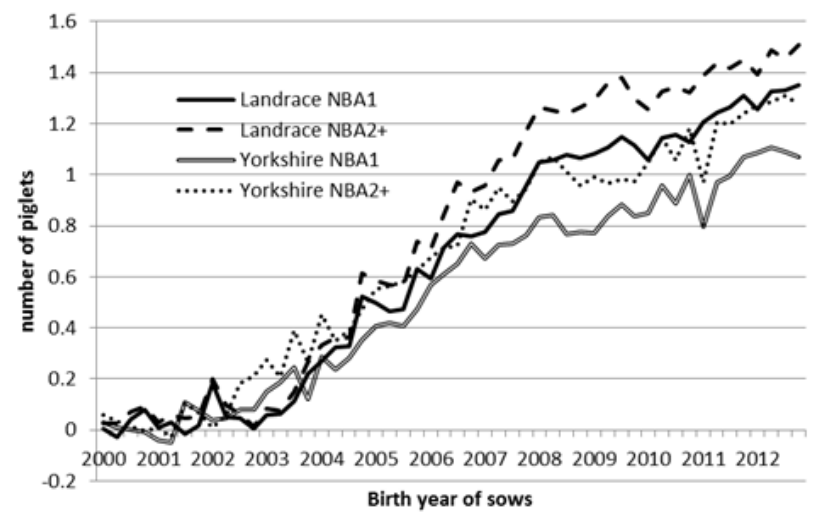

Figure 1. Genetic trend for NBA1 and NBA2+ by breed from 2000 to 2012

Estimates of genetic gain for NBA were greater in later parities and lower in the first parity, and, conversely - for LW, the genetic gain in LW1 was greater than in LW2+. From 2003 , for LL breed sows, a positive response was detected in 
the traits $\mathrm{NBA}$ and $\mathrm{NBA} 2+$, namely, the average genetic gain during 10 years increased up to 1.4 and 1.5 piglets or 0.14 and 0.15 piglets per year, respectively (Fig. 1). Overall, estimates of the genetic trend for NBA in LL sows were greater than in LY sows. LY sows in the trait NBA2+ reached the same trend line that LL sows reached in NBA1, and genetic change in NBA2+ for LY breed sows was up to 1.3 piglets in 2012 .

From 2000 to 2005 , fluctuations in LW were about $1.2 \mathrm{~kg}$ for $\operatorname{LL}(-0.6 \mathrm{~kg},+0.58 \mathrm{~kg})$ and $2 \mathrm{~kg}$ for $\mathrm{LY}(-0.4 \mathrm{~kg},+1.4 \mathrm{~kg})$. Starting from 2005, the genetic response was positive, and in 2012 reached $1.7 \mathrm{~kg}$ for $\mathrm{LW} 1$ and $1.2 \mathrm{~kg}$ for LW2+ or 0.21 and $0.15 \mathrm{~kg}$ per year, respectively, for LL sows; and $1.4 \mathrm{~kg}$ for LW1 and $1.5 \mathrm{~kg}$ for LW2+ or 0.18 and $0.19 \mathrm{~kg}$ per year, respectively, for LY sows (Fig. 2).

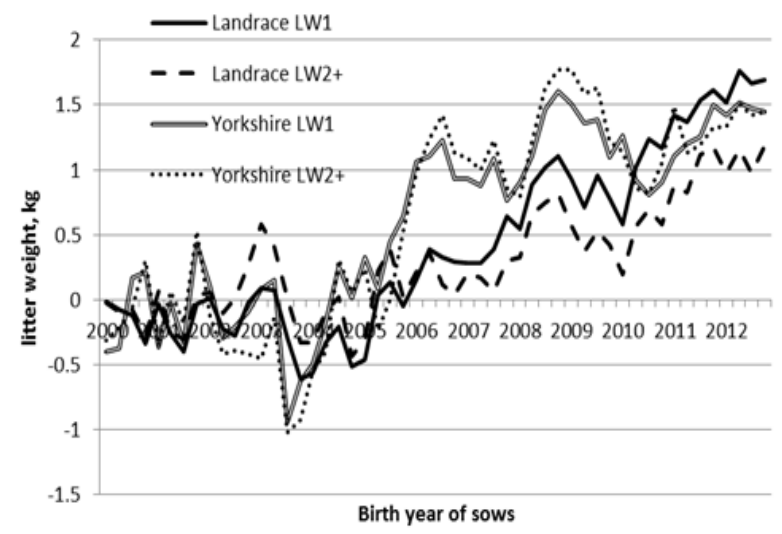

Figure 2. Genetic trend for LW1 and LW2+ by breed from 2000 to 2012

During the last ten years, WCI was improving in the breeding (nucleus) herds, and genetic response in 2012 was -2.5 days for LL sows and -0.95 days for LY sows (Fig. 3).

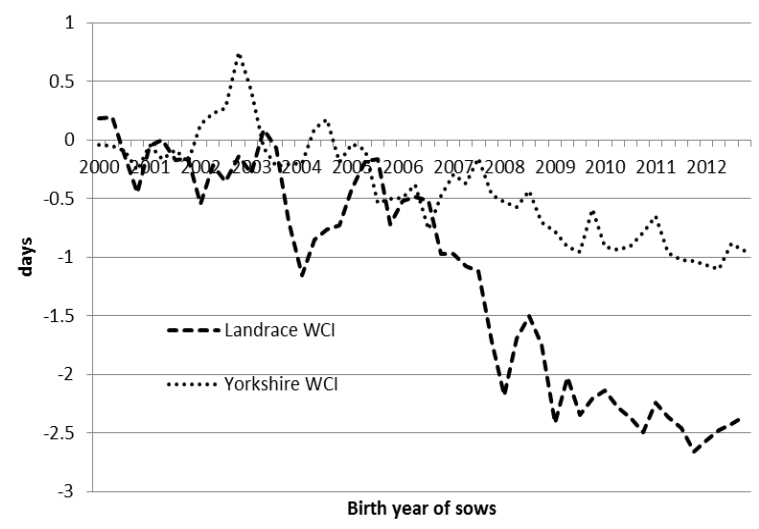

Figure 3. Genetic trend for WCI by breed from 2000 to 2012

\section{Discussion}

The records in the first parity (NBA1) and in later parities $(\mathrm{NBA} 2+)$ were treated as separate traits and were analysed separately. The results indicated the heritability for both traits (NBA1 and NBA2+) was low 0.05 and 0.1 .

Heritability estimates in our study are close to those reported by Hamann et al. [5]. In their research, heritabilities for NBA1 and NBA2+ in German Landrace sow population were 0.15 and 0.11 , respectively. Whereas Serenius et al. [10] obtained the same heritability estimates for the total number of piglets born in Finnish Landrace swine population.

For the traits NBA1 and NBA2+, the genetic variance was 0.77 and 0.84 in LL sows, and 0.45 and 0.79 in LY sows, respectively, which was higher than that in the investigation by Chen et al. [3]. In LL and LY populations, selection for NBA1 and NBA2+ has been done already for 15 years. Subsequently, direct selection for NBA reduced the trait variability, which as a result decreased the additive genetic variance to less than 1 .

According to the investigation of Holm et al. [6] on Norwegian Landrace breed, the decrease in age at first service decreases the NBA in the first parity $\left(r_{\mathrm{g}}=0.17\right)$; however, age at first service (AFS) is available earlier in the sow life, therefore the researchers concluded that AFS, litter size, and weaning-to-first service interval after first parity should be included in the fertility index. At present, the selection traits for Norwegian Landrace sow reproduction are LW at week three, number of teats, and the three before-mentioned traits.

The farrowing and insemination data recorded in the LL and LY nucleus herds suggested that AFS or AFF could be a potential genetic trait to improve the efficiency of the sows per unit time. The heritability of AFF was higher than for NBA1: 0.21 with genetic variance 187.7 for LL breed, and 0.20 with genetic variance 175.3 for LY breed. This means the selection for this trait could be successful.

The number of teats is not included in the genetic evaluation of the LL and LY sows; however, the CCC is performing selection of the number of teats (at least 14 teats). Lundeheim et al. [7] found that litter size did not genetically correlate with the number of teats (functional or total number); however, including the number of functional teats in the sow genetic evaluation could easily result in a substantial genetic progress, because the heritability of traits was slightly higher than 0.3 .

The number of weaned piglets is not included in the genetic evaluation of the LL and LY sows, because cross-fostering is used in the nucleus herds; however, this trait as a factor is included in the WCI evaluation model. LW is one of the traits used in the genetic evaluation of gilts and sows, which characterises the mothering ability of sows.

WCI was analysed by the single-trait model. Heritability estimate for this trait was low: 0.04 for LY and 0.12 for LL. Also in different studies reported before, heritability for WCI tended to be low $[1,2,8]$. The heritability for WCI after first parity was higher than after second parity [12]. If heritability and repeatability are low, it is appropriate to analyse the first-second parity conception interval and later parities conception interval separately, and they should be considered as separate traits. WCI after first parity is included as a separate trait in the LL and LY sow breeding evaluation, because this trait indirectly improves the trait NBA2. As our previous investigation showed, genetic correlation between WCI and NBA2 was negative $\left(r_{\mathrm{g}}=-0.40\right)$, which means that sows with a smaller WCI interval had a higher NBA in the second parity [12]. 
Lundgren et al. [8] observed that sows with genetic capacity for a high body condition at weaning may produce more piglets in the second parity, which suggests that it is reasonable to focus more attention on the LL and LY sow body condition before and after weaning of piglets and to measure these values.

In general, selection for the reproduction traits of LL and LY sows is effective. Throughout the 15-year use of BLUP in Landrace and Yorkshire populations, the average selection gain for NBA, LW, and WCI was low but positive. The low response to selection can be explained by the low heritability estimates for reproduction traits in the first and later parities. Further genetic improvement of reproduction traits can be possible due to strong selection on NBA, LW, and WCI. The next step in sow improvement can be due to including new traits, such as AFF and sow body condition before and after weaning of piglets, in the routine sow breeding evaluation.

Heritability estimates for reproduction traits ranged from low to moderate, and calculated genetic parameters are suggested to use in the actual gilts and sows' breeding evaluation at the CCC, which may increase the accuracy of estimated breeding value.

\section{Acknowledgements}

This work was supported by the Latvian Ministry of Agriculture. The Pig Breeding Centre is acknowledged for providing data for this study.

\section{References}

[1] Abell C.E., Mabry J.W., Dekkers J.C.M., Stalder K.J. (2012). Genetic and phenotypic relationships among reproductive and post-weaning traits from a commercial swine breeding company. Livestock Science, 145(1-3), 183-188.

[2] Adamec V., Johnson R.K. (1997). Genetic analysis of rebreeding intervals, litter traits, and production traits in sows of the National Czech nucleus. Livestock Production Science, 48(1), 13-22.

[3] Chen P., Baas T.J., Mabry J.W., Koehler K.J., Dekkers J.C.M. (2003). Genetic parameters and trends for litter traits in U.S.
Yorkshire, Duroc, Hampshire, and Landrace pigs. Journal of Animal Science, 81, 46-53.

[4] Grandinson K., Rydhmer L., Strandberg E., Solanes F. X. (2005). Genetic analysis of body condition in the sow during lactation, and its relation to piglet survival and growth. Animal Science, 80, 33-40.

[5] Hamann H., Steinheuer R., Distl O. (2004). Estimation of genetic parameters for litter size as a sow and boar trait in German herdbook Landrace and Pietrain swine. Livestock Production Science, 85(2-3), 201-207.

[6] Holm B., Bakken M., Vangen O., Rekaya R. (2005). Genetic analysis of age at first service, return rate, litter size, and weaning-to-first service interval of gilts and sows. Journal of Animal Science, 83, 41-48.

[7] Lundeheim N., Chalkias H., Rydhmer L. (2013). Genetic analysis of teat number and litter traits in pigs. Acta Agriculturae Scandinavica, Section A - Animal Science, 63:3, $121-125$.

[8] Lundgren H., Fikse W.F., Grandinson K., Lundeheim N., Canario L., Vangen O., Olsen D., Rydhmer, L. (2014). Genetic parameters for feed intake, litter weight, body condition and rebreeding success in primiparous Norwegian Landrace sows. Animal, 8, 175-183.

[9] Meyer, K. (2010). Wombat. A program for mixed model analyses by restricted maximum likelihood. University of New England, Armidale, Australia.

[10] Serenius T., Sevón-Aimonen M.L., Mäntysaari E. A. (2003). Effect of service sire and validity of repeatability model in litter size and farrowing interval of Finnish Landrace and Large White populations. Livestock Production Science, 81(2-3), 213-222.

[11] Su, G., Lund, M.S., \& Sorensen, D. (2007). Selection for litter size at day five to improve litter size at weaning and piglet survival rate. Journal of Animal Science, 85(6), 1385-1392.

[12] Ziedina I., Jonkus D., Paura L. (2011). Genetic and phenotypic parameters for reproduction traits of Landrace sows in Latvia. Agriculturae Conspectus Scientificus 76(3), 219-222.

[13] Veide D., Eiduks U., Bokvalds A. (2010) Latvijā audzēto cūku selekcijas programma. 2011.gadam un tuvākai perspektīvai līdz 2016.gadam. (in Latvian) http://www.ccc.lv/lv/selekcija/jauna\%20programma pec 201 0_a_u.pdf 